\title{
Popular practices in child care: mothers' perceptions
}

\author{
Práticas populares no cuidado infantil: percepção das mães
}

Angélica Yukari Takemotoํㅜ Nara Fabieli Zarpelon ${ }^{1}$, Edilaine Giovanini Rossetto ${ }^{2}$

Objective: to describe the perception of mothers about the use of popular child care practices in the home. Methods: qualitative research, performed with ten mothers of children up to two years old. Data were collected through interviews in a primary health care unit, which were recorded and submitted to content analysis. Results: three categories emerged from the analysis of the discourse: 1) Family roles in child care; 2) Popular practices as a family culture in child care; and 3) The belief in healing spells as a resource in popular practice. Conclusion: the use of popular practices remains strong in the social and cultural context of families, and is especially influenced by grandmothers. Thus, there is a need for instrumentation of the health team for the good use of these practices in favor of the promotion of child health and recognition of nursing in its professional practice.

Descriptors: Child Care; Family; Medicine, Traditional; Nursing.

Objetivo: descrever a percepção das mães no uso das práticas populares prestados à criança no domicílio. Métodos: pesquisa qualitativa, realizada com dez mães de crianças até dois anos. Os dados foram coletados por meio de entrevista gravada em uma unidade básica de saúde e submetidos à análise de conteúdo. Resultados: três categorias emergiram a partir da análise dos discursos: 1) Os papéis da família no cuidado à criança; 2) As práticas populares como cultura familiar no cuidado infantil; e 3) A crença em benzedeiras como recurso de prática popular. Conclusão: o uso das práticas populares se mantém forte no contexto social e cultural das famílias, principalmente influenciado pelas avós. Assim, há necessidade de instrumentalização da equipe de saúde para o bom uso dessas práticas a favor da promoção da saúde infantil e o reconhecimento da enfermagem em sua prática profissional.

Descritores: Cuidado da Criança; Família; Medicina Tradicional; Enfermagem.

\footnotetext{
${ }^{1}$ Faculdade Guairacá. Guarapuava, PR, Brazil.

${ }^{2}$ Universidade Estadual de Londrina. Londrina, PR, Brazil. 


\section{Introduction}

Child care in the home context is permeated by beliefs, myths and customs resulting from family cultural tradition. The adoption of home-based measures in child care comes from the easy access to such therapies. In fact, child care consists in a range of beliefs shared by people in different groups. When care is provided concomitantly by a sum of people, the cultural volume expands even further because the shared understanding provides interpretations that guide the experiences of the family ${ }^{(1-2)}$.

Madeleine Leininger's Cultural Care Theory postulates that nursing must resort to cultural know-ledge in order to promote care. Leininger's theory harmoniously associates care to direct it to nursing practices. In other words, it is necessary to recognize the existence of the professional care system, but also of the popular care system ${ }^{(3-4)}$.

It is worth noting that nursing plays a very important role in child care because it promotes health education through educational activities aimed at the population and dissemination of knowledge. Because nurses are professionals who are close to the community, health education is an inherent part of their work.

To this end, nursing professionals must understand the profile of the public that is being approached and its level of understanding so that popular knowledge and the local cultural influences have space in the negotiation of the practice of the care ${ }^{(4)}$. Given the above, the following question arises: Are popular practices in child care at the home context used?

The knowledge of these characteristics can provide important subsidies for the performance of nurses, in the sense of taking the culture in which the individuals are inserted into account so as to provide quality nursing care. When it comes to child care, this cultural influence becomes even more evident. It is essential to know the socio-cultural context of the mothers and identify their knowledge and care practices so that their beliefs and customs may be included in the health care practice.
Thus, the present study aimed to describe the perception of mothers about the use of popular child care practices at the home.

\section{Methods}

The qualitative approach was adopted in this research, which was carried out in a unit where the Family Health Strategy is implemented, located in the municipality of Irati, Paraná, Brazil. This municipality has 19 active Basic Health Units, and five of these units work with the Family Health Strategy.

The study included women who had children in the age range from zero to 24 months and who were enrolled in the family health program of the Family Health Strategy. The women were randomly selected. The choice of this age group was due to the greater exposure of these children to care permeated by cultural values $^{(4)}$. The inclusion criteria were mothers aged 18 years and over, who resided in the municipality studied, and who accepted the invitation to participate in the study. There were no criteria for exclusion of the participants. Ten mothers participated in the study. This sample size followed the principle of data saturation ${ }^{(5)}$, which occurs when the statements do not add any new information.

Data were collected between September and October 2017. Mothers were approached by one of the researchers after the nursing consultation, initially explaining the research, and then providing the Informed Consent Term for signing in a private place in the basic health unit.

Open questions were used in the semi-structured interview, based on the following guiding questions: What do you understand by care? What are the traditional customs that your family uses in the care of your child? How have the use of healing prayers and/ or healing spells influenced the care of your child? The interviews lasted on average 40 minutes and were recorded upon permission of the interviewees.

After that, the speeches were heard and transcribed verbatim using the Word $₫$ text editor softwa- 
re. Then, the statements were submitted to Minayo's thematic analysis for organization of thematic categories $^{(6)}$. The anonymity and secrecy of the identity of each participant were preserved. They were identified by the letter $\mathrm{M}$ (mother) followed by a number corresponding to the order of participation in the interviews.

The thematic analysis proposed by Minayo seeks to highlight the importance of communication through fundamental themes that are addressed in the course of the research, with statements on the subject analyzed. It also aims to discover the nuclei of meaning that make up the communications whose speech is meaningful to reach the objective of the study ${ }^{(6)}$.

The study respected the formal requirements of Resolution 466/12 of the National Health Council, considering the regulatory norms of research involving human beings, and was approved by the Research Ethics Committee of the State University of the Midwest, according to Opinion no 2,225,146.

\section{Results}

Among the ten mothers participating in the study, the age range was between 21 and 44 years, and the majority had incomplete elementary education, low monthly family income, and was married and primiparae.

After the analysis of the speeches, three categories were created: Family roles in child care; Popular practices as a family culture in child care; and The belief in healing spells as a resource in popular practice.

\section{Family roles in child care}

The birth of a baby mobilizes the whole family around its health care. When asked about the care given to the child, most mothers cited measures related to food and hygiene issues. Considering the importance of these two issues, as regards the growth and development of this new being within the family, the participants revealed the following testimonies: To care for the child is to give the food at the right time, to maintain the baby's weight of the month, make sure that everything the child needs be available, take it to the doctor if necessary, always seeing the pediatrician to check if everything is OK with the child (M1). If the baby is crying, see what it is, if it is a pain, give medicine, and being always attentive, always around, all the time (M2). Taking him to the doctor, caring when he gets sick, giving him a good environment for living... it is all we do for him (M6). To follow the medical prescriptions correctly, to attend consultations until the baby completes one year of age... I never missed a single a consultation of my children (M7).

In another context, family members assume a helping role in the care. The presence of the companion seemed indispensable for the care of the child: I receive the help of my husband, he... goodness... he is not the father, but he treats the child as if he were the father. He works out, but even so, at night he gives her attention, he plays with her, he is there, pampering her like a father (M1). I get a little like this, my husband is like that, he takes care of... if I go to do something and if I need help, he helps me (M4). So, in the everyday routine, it's just me and my husband, he also helps me (M6).

And participation of people beyond the immediate family was also highlighted in the lines: The grand$m a$, who is my mother-in-law... she helps me in everything, in anyway... everything I need, she is here helping me... if I'm at home... the grandma stays with her for me to do the housework... she feeds her, bathes her... she does everything I do (M4). My mother helps me, I live with her, and she stays with my daughter for me to go to college (M8).

\section{Popular practices as a family culture in child care}

Considering the possibility of children's exposure to the care provided by their families, the use of beliefs and spells demonstrated the influence of previously practiced customs, even outweighing professional guidelines: I do what my mother teaches me to do, everything... the way I take care of her is the way my mother taught me, how to use the picão, the teas when she has colic, these things (M1). There are spells that my family does, such as giving the child a fright, when he has hiccups, those things that they did to me when I was a child, and that they now do with my son (M5). I always ask my mother to "take out the fright", not necessarily in person, my grandmother used to do that, and passed it to my mother, she is the one 
who does it now... she prays pouring coal into the water, it helps a lot. There are days when he is very scared, and she does that, and he gets a lot better, has less tantrums (M6). I did what the nurse taught me, use alcohol with a cotton swab right there on the little navel, and I also wrapped it. She said it was not necessary, on the day of the first consultation she took the wrap off, but my mother-in-law told me it was necessary, otherwise it would be swollen, so I left it (M10).

In the perception of one of the mothers, this influence results mainly from the lack of experience in caring for the child: What my mother and my mother-in-law tell me what I have to do I do, because they are more experienced, they raised us, they know. People who are first-time moms do not have much experience to deal with this... the way of doing things, giving tea when they have colic, spells to do when they have hiccups... they know more than we do(M3).

In this sense, the presence of popular practices has been perceived very frequently. The dressing of the umbilical stump and the various spells are examples of the main care measures adopted. The following statements were observed: To heal, nothing was needed, thanks to God it healed very easily... was taken to take the air out of the navel, a bracatinga sawed branch was made... they are three chopsticks... and even nine if need be. Put the little diaper on top of the navel, then we put the little stick, pressing the little navel, but it is not necessary let the stick in, it is slightly, it is not supposed to affect anything... then that thick navel gets smaller (M7).

Risks to the child caused by exposure to such folk healing methods were also observed, such as the possibility of acquiring neonatal tetanus: She scraped $a$ red brick and mixed it with water until it formed a paste and put that dough on top of her little navel to dry faster... (M6).

Another recurring practice among the interviewees was the use of teas: Dill, just for bellyache, I have not used other teas yet, but if it depended on my mother-in-law, we would have already given other teas. She told me that he is getting thirsty, that I have to give it already, that he is now understanding, he is five months old now, he is already eating, so we can start with another type of tea (M3). Chamomile tea to calm down... I also give the fennel tea after eating food, they say it helps in digestion, prevents bellyache (M8). Since the day I came from the hospital, I got home, the tea was there ready. But we only gave him dill, because of the bellyache; he used to have much pain (M10).
Regarding the treatment of worms, some practices were adopted: You make mint tea, do not sweeten it, and put two drops of vinegar and give it to the child. She is going to feel that strong colic and if she has worms, they will be expelled... there is the healing spell that gets rid of worms, so... the only necessary thing is the right moon, which is the waning moon (M1). You boil a few mint leaves and three cloves of garlic in a little of water... and then you give the child a spoon only per day, for three days, sweetened with a little of honey. There is also milk with mint... you put a sprig of mint in a little of milk, boil, and when it is cooling, still warm, sweeten it with honey, a little bit of honey... the only thing is that this has to be repeated during seven days to get completely rid of worms (M6). We have to give mint tea to avoid them, but if you have the chance, take the child to the healer, she makes a ball of yarn, rolls it, then she cuts it and throws it on the plate, and prays, so that those 'worms' that were cut do not come back (M7). You have to cut if they have not attacked yet. If they have already attacked, you first have to calm down the 'worms', then cut it, that's what they say... if you cut it while the worms are stirred, we may drown the child. And about the medicine, we have to give it on the right moon, otherwise it's of no use... (M10).

And, lastly, the last popular practice used in the care of children under two years of age was related to neonatal jaundice, as observed in the following statements: First we tried the sun bath, behind the glass, and picão tea, that the old ones used to make the child get better; they say it helped the child (M5). We did not have it, but I would put my ring in the bath every day to bathe him, to prevent... but if he had... I'm only aware of the bath in picão tea (M6).

The following report was also observed: She stayed under the light there in the hospital only for two days; after she left, she did not have it anymore, but I bathed her with bean broth. We add one big spoon in the water for each day of life, and bathe the child for one day, to avoid that the yellowish aspect come back... if that aspect returned, we had to bathe the child in the tea of picão root, to avoid the aspect from returning (M7).

\section{The belief in healing spells as a resource in popular practice}

The importance of the belief in healing spells was perceived in the testimonies as first instance. Always that I can I take her to healers in the waning moon, to ward 
off the evil eye... but I always take her first there... because those things happen, children have frights, things like this, I take her to all the healers, because I believe a lot on this (M1). I believe, I take the baby as soon as possible to the healer to avoid breakdown, pouring wax, and if there's anything else, she'll pass the spell to us, you know... things like that (M6).

As the family is adept to the use of healing spells, the mother also believes that the healers are important and influential for the care of her child. I took him to be blessed, because my mother-in-law always said I had to take him there. It was when they saw that he had his little chest open... she spilled wax on him... then she saw he had the chest open, then she took him there to her bed, and with the strip, put it on his arms, he measured from one arm to the other, and put it on his little chest, and then closed the chest. Then I started to believe in these things of healing spells (M2). I am always looking for a healer to avoid frights and breakdown. My mother took me there when I was little, so I think they make a difference. The spell of air in the navel was very good, because she used to cry every night in the first days, she would cry, she cried a lot, and after the spell, she stopped. It was a string she measured there on her belly and burned it. Then I went two days, and she put soil on her, like this, she crossed the earth, and cut it off. That was the afternoon, before the sun went down, that she asked me to go. In her case, that helped a lot (M9). I always go there; my mother used to take me there when I was little... I took him to the healer and he saw that he had his little chest open, he measured the string with open arms, and then when he crossed his arms on the chest, he did not close the measure of the string, and when it is like that, it is because his chest is open, he said, then he passed the strip, and he stopped crying (M10).

In one of the testimonies, it was seen that the belief in healing prayers, besides spells, led to the cure of diseases. My mother-in-law and my grandmother believed in healing prayers, and thus I came to believe too... it cures anemia. The healer takes us to the middle of the bush, first she measures the child with a string, then she takes it to the bush and finds a vine, ties the string in the vine, and makes the child hold the string and pass around the vine, three, six or nine times around the string, and she does the prayer as well, and the string has to be tied there, this eliminates anemia (M7).

\section{Discussion}

The fact that this article presents information only from a small municipality, which generally favors the imposition of cultural influence, as well as the focus of the study directed only to popular beliefs in child care, imply limitations to the study, preventing the generalization of the data. Further investigation in other municipalities, of medium and large size, is recommended to verify if this predominance of popular beliefs persist despite scientific knowledge. Further studies with other population groups are necessary to identify the existence of popular beliefs also among other clienteles.

The influence of sociocultural characteristics on the perceptions about the health-disease process should be explored in the community under a careful perspective of cultural and behavioral singularities of the population. When popular knowledge and the presence of folk healers are so strong, the implementation of actions can be considered a challenging task for health professionals, especially the nurse. It is up to these professionals to understand the way of thinking and acting of individuals before their problems and health care, associating such popular knowledge with scientific information, in order to facilitate their care practice.

The results of the present study corroborate with other investigations that emphasize the use of popular knowledge by families and the belief in healers as a primary care resource when it comes to child care. Because the use of these strategies brings numerous benefits, experienced by family traditions in former times, there is a feeling of satisfaction and increased confidence to enjoy these practices with their children $^{(7-8)}$.

These cultural practices full of symbols, meaning, tenderness and affection can express the perception of health and illness during motherhood, as well 
as social roles that are defined as a consequence of the experience of giving birth ${ }^{(9)}$. Such practices passed on from generation to generation impose difficulties for the nursing team finds to provide due care, thus generating conflicts with families ${ }^{(10)}$.

In the caregiver's conception, the promotion of care for good child development involves cultural practices that are impregnated in the way of carrying out care, combining a series of scientific care measures with popular practices that are still used in all phases of the evolutionary cycle of children ${ }^{(4)}$.

Given the above, a sense of responsibility of the family for the health care of its members in the different phases of the life cycle is clear, understanding that the health-disease process of the individual must be attended professionally through family responsibility. Thus, the family plays a prominent role in primary health care and in the care of its members.

Despite all technological advancement, popular resources are credible because they often respond to the population's expectations. It was observed that most mothers used old home-based measures already tested by the community to solve the problems they faced on a daily basis ${ }^{(11)}$. Sometimes, the use of popular practices overrides scientific knowledge in child health care ${ }^{(9)}$, and this can be considered harmful to child care.

Cultural and family values, coupled with a vulnerable socioeconomic situation, lead families to learn and resort to these resources as the first form of treatment of health problems in the daily care of children. In a research carried out in a riverside community in Amazonas, the results indicated that popular practices such as the use of medicinal plants are widely spread in the treatment of diseases as a result of the difficult access to health services by this type of community; thus, this resource is held as first choice in the treatment of children affected by pathologies ${ }^{(8)}$.

Another very strong cultural factor in the study is the presence of the folk healers, because their knowledge often opposes to the guidelines provided by health professionals. They are people with great in- fluence in the community where they live as holders of popular knowledge. They are known as people of great faith and with a greater connection with the divine plan, which is why they can identify diseases and treatments. Their knowledge is passed on from generation to generation, and the belief in their power, coupled with the belief in healing through a Supreme Being, strengthens their standing before the community.

The strength of healers in the community has been solidified on a two-fold belief: the trust of individuals in the healers and in the power of their prayers; and the faith of the healer in God, which ensures that their requests will be accepted. Some authors explain that such belief is a form of faith, and believing in the sayings, in the everyday life, means to incorporate this thought ${ }^{(12)}$.

Because they are placed between the traditional medicine and the religious space, healers deal with the real and practical problems of people's daily life. For this reason, their presence promotes strength and confidence to the community. People turn to them because they trust their skills and their knowledge about home medicine ${ }^{(8,13)}$.

Before such a reality, it is possible to infer the importance of popular practices and healers as a significant link between the population and the formal health system. This shows that the existence of these elements is not limited to distant, isolated places and to the lack of formal health care, but it is rather a cultural phenomenon that has always existed and which will hardly disappear, especially when it comes to child care ${ }^{(14)}$.

In view of all the popular practices and the belief in healers, there is a lack of guidance to mothers with respect to the process of child growth and development, as well as to actions in case of the emergence of pathologies. In this context, it is up to health professionals to improve the methods used by the society in which they are inserted, seeking to respect the presented beliefs and offer a mutual exchange of knowledge. This content should be addressed in all 
health education opportunities, especially in nursing consultations.

Child health care is still in the process of construction, as it is health care in general, in a network model to favor family inclusion and comprehensive care. Care can be developed by health professionals and by the community in general. This practice implies the exchange of technical and scientific knowledge, as well as the exchange of experiences and sharing of information among all involved in the action ${ }^{(15)}$.

Thus, nurse take on an important role in assisting the population, as they promote health education activities, health promotion and prevention actions, fulfilling their duty of guiding the population and disseminating knowledge. Health professionals must pay attention to the fact that, when arriving at a certain place, it is necessary to value the local culture and the common knowledge of the people in order to achieve the desired success in their health education actions ${ }^{(9)}$.

In this context, the Cultural Care Theory developed by nurse and anthropologist Madelaine Leininger can be used creatively with individuals, groups and/or families. According to this theory, it is recommended that nursing improves health care by taking cultural diversity, and not merely the disease, into account in its actions ${ }^{(16)}$.

Nursing consultations become opportune moments for families to present and clarify their doubts. Through childcare, nurses have the possibility to follow-up the growth and development of the children, evaluating the care applied to these new beings, with the possibility of exchanging experiences ${ }^{(16)}$.

In a study carried out in Ceará, the authors presented a protocol to be used in childcare. This was a guiding tool for nurses that systematized and standardized care. The results pointed out that the application of a protocol can fill the gaps in childcare, allowing a holistic and systematized assistance during childcare consultations $^{(17)}$.

Therefore, knowing the experiences of mothers about the care provided to their children is extremely important for nurses to direct the dialogue, and to make it possible to improve the knowledge of families, through health education, enabling the establishment of new forms of care where the beliefs and cultures experienced by them are taken into account ${ }^{(9)}$.

The dialogue between the two universes, namely, popular and scientific knowledge, proves to be an essential practice for health promotion in primary health care. The consideration of cultural beliefs and family practices favors the perception of user as co-responsible in their therapeutic process, besides facilitating the approach between health professionals and clients ${ }^{(18-19)}$. It is, in fact, critical to know the cultural context, beliefs, rituals and way of life of users and their families in order to establish an innovative approach to caring ${ }^{(18-19)}$.

It is noteworthy that the relationship between mothers/families and nurses is placed in the national and international literature as an essential piece to strengthening the mother-baby bond. This is so because these professionals are trained to promote assistance and encourage parental involvement in child care, facilitating the reciprocity, the sense of responsibility, and the adequacy of maternal responses to the child. Therefore, mothers who receive support from nurses are more likely to build a positive and healthy relationship with their child ${ }^{(8,20)}$.

\section{Conclusion}

The study showed that the use of popular practices, including the role of healers, remains strong in the social and cultural context of families, mainly influenced by grandmothers. There is, therefore, a need for instrumentation of the health team to make good use of these practices in favor of child health promotion and recognition of nursing in its professional practice.

\section{Acknowledgements}

To the women who participated in the study and to the staff of the basic health unit for their collaboration to the present study. 


\section{Collaborations}

Takemoto AY and Zarpelon NF contributed to the conception and design of the study, analysis and interpretation of the data, writing of the article and critical review of relevant intellectual content. Rossetto EG contributed to the writing of the article, relevant critical revision of the intellectual content and approval of the final version to be published.

\section{References}

1. Moura THM, Vasconcelos MGL, Pontes CM, Guedes TG, Ximenes LB, Leal LP. Cuidados domiciliares para promoção da saúde da criança no Brasil: revisão integrativa. Online Braz J Nurs. 2014; 13(4):686-98. doi: http://dx.doi. org/10.5935/1676-4285.20144808

2. Andrade RD, Santos JS, Maia MAC, Silva MAI, Veríssimo MLÓ, Mello DF. Home visit: care technology used by nurses to advocate for child's health. Texto Contexto Enferm. 2015; 24(4):11308.doi:http://dx.doi.org/10.1590/01040707201500000120015

3. Melo FMS, Santos MP, Sousa LB, Holanda VMS, Araújo MFM, Joventino ES. Experiências de estudantes internacionais ao gestar longe do seu país de origem. Av Enferm. 2018; 36(3):25564. doi: http://dx.doi.org/10.15446/av.enferm. v36n3.65010

4. Oliveira EAR, Rocha SS. O cuidado cultural às crianças na dinâmica familiar: reflexões para a Enfermagem. R Interd [Internet]. 2015 [citado 2019jan. 07];8(1):227-33. Disponível em: https:// revistainterdisciplinar.uninovafapi.edu.br/index. php/revinter/article/view/302/pdf_198

5. Fontanella BJB, Ricas J, Turato ER. Amostragem por saturação em pesquisas qualitativas em saúde: contribuições teóricas. Cad Saúde Pública. 2008; 24(1):17-27. doi: https://doi.org/10.1590/ s0102-311x2008000100003

6. Minayo MCS. 0 desafio do conhecimento: pesquisa qualitativa em saúde. São Paulo: Abrasco; 2013.
7. Lima CAB, Lima ARA, Mendonça CV, Lopes CV, Heck RM. The use of medicinal plants and the role of faith in family care. Rev Gaúcha Enferm. 2016; 37(spe):e68285. doi: dx.doi.org/10.1590/19831447.2016.esp.68285

8. Lima RFS, Turrini RNT, Silva LR, Melo LDS, Augusto SI. Popular healing practices and medical plants use for riparian mothers in early childhood care. Rev Pesqui Cuid Fundam Online. 2017; 9(4):115463. http://dx.doi.org/10.9789/2175-5361.2017. v9i4. 1154-1163

9. Souto MC, Zaccara AAL, Fernandes MA, Platel ICS, AlbuquerqueTM, FelixZC.Consulta de enfermagem para a criança e o idoso: revisão integrativa da literatura. R Bras Ci Saúde. 2014; 18(3):241-8. doi: doi.org/10.4034/RBCS.2014.18.03.08

10. Santos AL, Teston EF, Cecílio HPM, Serafim D,Marcon SS. Grandmothers' involvement in the care of children of adolescent mothers. Rev Min Enferm. 2015; 19(1):60-4. doi: http://www. dx.doi.org/10.5935/1415-2762.20150005

11. Christoffel MM, Silva LR, Silva LR, Ferreira ACGV, Macedo EC. Infant colic: descriptive study of maternal care practices for pain relief. Rev Enferm UFPE online [Internet]. 2013 [cited Jan. 13, 2019]; 7(10):5876-82. Available from: https:// periodicos.ufpe.br/revistas/revistaenfermagem/ article/view/12212/14798

12. Jesus ACP, Bandeira LPL, Araújo MFM, Gubert FA, Vieira NFC, Rebouças CBA. Popular knowledge in care of the newborn with focus on health promotion. Rev Pesqui Cuid Fundam Online. 2013; 5(2):3626-35. doi: http://dx.doi. org/10.9789/2175-5361.2013.v5i2.3626-363

13. Azevedo GX. Das relações entre a cultura popular e as benzedeiras. Fragm Cult. 2016; 26(2):231-8. doi: http://dx.doi.org/10.18224/frag.v26i2.4897

14. Rocha LS, Rozendo CA. The popular and official health systems from the viewpoint of faith-based healers. Rev Enferm UFPE online [Internet]. 2015 [cited Jan. 13, 2019]; 9(supl.1):336-42. Available from:https://periodicos.ufpe.br/revistas / revistaenfermagem/article/view/10344/11052 
15. Couto TA, Santos FPA, Rodrigues VP, Vilela ABA, Machado JC, Jesus AS. Health education under perspective of family health teams users. Rev Enferm UFPE online [Internet]. 2016 [cited Jan. 13, 2019]; 10(5):1606-14. Available from: https:// periodicos.ufpe.br/revistas/revistaenfermagem/ article/view/11156/12674

16. Rocha GST, Araujo Filho ACA, Nunes BMVT, Rocha SS. Educational practice nurses in nursing consultation child in perspective Madeleine Leininger. Rev Enferm UFPI. 2015; 4(2):124-9. https://doi. org/10.26694/reufpi.v4i2.3522

17. Gubert FA, Santos DAS, Pinheiro MTM, Brito LLMS, Pinheiro SRCS, Martins MC. Development of a nursing protocol for child care consultations. Rev Rene. 2015; 16(1):81-9. doi: http://dx.doi. org/10.15253/2175-6783.2015000100011
18. Badke MR, Somavilla CA, Heisler EV, Andrade A, Budó MLD, Garlet TMB. Saber popular: uso de plantas medicinais como forma terapêutica no cuidadoàsaúde. RevEnfermUFSM.2016;6(2):22534. https://doi.org/10.5902/2179769217945

19. Chibante CLP, Santo FHE, Santos TD, Porto IS, Daher DV, Brito WAP. Knowledge and practices in care focused on individuals with wounds. Esc Anna Nery. 2017; 21(2):e20170036. http:// dx.doi.org/10.5935/1414-8145.20170036

20. Reichert APS, Rodrigues PF, Albuquerque TM, Collet N, Minayo MCS. Bond between nurses and mothers of children younger than two years: perception of nurses. Ciênc Saúde Coletiva. 2016; 21(8):2375-82. doi: https://doi. org/10.1590/1413-81232015218.0766201 